\title{
Supramolecular Facilities to Melanoma Cells B16F10 with Nanoparticles of a DEAE-Dextran-MMA Copolymer-Paclitaxel Complex
}

\author{
Yuki Eshita ${ }^{1 *}$, Rui-Cheng $\mathrm{Ji}^{2}$, Masayasu Onishi ${ }^{3}$, Masaaki Mizuno ${ }^{4}$, Jun Yoshida ${ }^{5}$, Naoji Kubota ${ }^{6}$ and Yasuhiko Onishi ${ }^{3 *}$ \\ ${ }^{1}$ Department of Infectious Disease Control, Faculty of Medicine, Oita University, 1-1 Idaigaoka, Hasama-machi, Yufu, Oita 879-5593, Japan \\ ${ }^{2}$ Department of Human Anatomy, Oita University, Faculty of Medicine, Oita, 879-5593, Japan \\ ${ }^{3}$ Ryujyu Science Corporation, 39-4 Kosora-cho, Seto, Aichi 489-0842, Japan \\ ${ }^{4}$ The Center for Advanced Medicine and Clinical Research, Nagoya University Hospital, 65 Tsurumai-cho, Showa-ku, Nagoya, Aichi 466-8560, Japan \\ ${ }^{5}$ Chubu Rosai Hospital, Japan Labour Health and Welfare Organization, 1-10-6 Komei, Minato-ku, Nagoya, Aichi 455-8530, Japan \\ ${ }^{6}$ Department of Chemistry, Faculty of Medicine, Oita University, 1-1 Idaigaoka, Hasama-machi, Yufu, Oita 879-5593, Japan
}

\begin{abstract}
A DEAE-dextran-MMA copolymer (DDMC)-paclitaxel complex was generated using paclitaxel as the guest and DDMC as the host. The resulting nanoparticles were $200-300 \mathrm{~nm}$ in diameter and are thought to be useful as an anti-cancer drug delivery system because of forming a stable polymeric micelle in water. The resistance of B16F10 melanoma cells to paclitaxel was confirmed using survival curve analysis. On the other hand, there is no resistance of melanoma cells to DDMC-paclitaxel complex. The DDMC-paclitaxel complex showed superior anti-cancer activity to paclitaxel alone. The cell death rate was determined using Michaelis-Menten Equations, as the complex promoted allosteric supramolecular reaction to tubulin. From our results, the DDMC-paclitaxel complex was not extensively degraded in cells, and achieved good efficacy as an intact supramolecular anti-cancer agent. The DDMC-paclitaxel complex showed high reactivity and specificity of anti-melanoma cells, depending on its supramolecular facilities.

The DDMC/PTX complex will be considered to be not degraded in cells, and represents the efficacy as supramolecular intact such as artificial enzymes having substrate-selective. It should be possible for other anti-cancer agents to offer the amplify effect from this supramolecular complex. These supramolecular facilities to melanoma cells will be very helpful to overcome cancer diseases.
\end{abstract}

Keywords: Supramolecular complex; B16F10 melanoma cells; DEAE-dextran-MMA graft copolymer; Paclitaxel; Nanoparticles

\section{Introduction}

Drug delivery systems (DDS) based on polymers are widely used as carriers for targeted drug delivery because of their Enhanced Permeability and Retention (EPR) effects [1] and their avoidance of the Reticuloendothelial System (RES) [2-3]. Recent studies have provided new insights into the intracellular distribution and efficacy of polymer-based DDS. For example, triple-labeled confocal microscopy of living cells revealed the localization of micelles (i.e., the drug-carrying polymer complex) in several cytoplasmic organelles, including the mitochondria, but not in the nucleus. Moreover, the cellular distribution of the micelle could be altered, and could increase the amount of drug delivered to the cells [4-6].

An exhaustive study of purified saccharose was conducted by the German chemist Dr. Willstatter. The purified enzyme is thought to consist of active groups of low and high molecular weight carriers (1920) [7]. However, the enzyme complex is possible because of the presence of large molecular subunits within the enzyme. Accordingly, supramolecules are now defined as proteins in which the low molecular weight subunit containing the active site is complexed with a high molecular weight carrier.

DEAE-dextran-MMA-copolymer (2-diethylaminoethyl-dextranmethyl methacrylate graft copolymer; DDMC) is a commonly used polymer that is generated by graft polymerization of MMA onto DEAE-dextran in water [8-10]. The resulting DDMC consists of 'hairy' nanoparticles with an amphiphilic domain (DEAE-dextran) and a hydrophobic domain (MMA polymer, PMMA) that form a polymer micelle [11]. It has been reported that DDMC is superior to other transfection with safety transfection efficacy by autoclaved as a non-viral carrier for gene introduction [12-18]. On the other hand, the paclitaxel is well known as a strong anticancer agent to introduce cancer cells to apoptosis in stabilization of tubulin (i.e., tubulin polymerization).

\section{Materials and Methods}

\section{Preparation of DDMC}

$2 \mathrm{~g}$ of 2-diethylaminoethyl (DEAE)-dextran hydrochloride (nitrogen content 3\%) derived from dextran ( $\mathrm{Mw} 500,000)$ was dissolved in $100 \mathrm{ml}$ of water, followed by the addition of $3.5 \mathrm{ml}$ of Methyl methacrylate (MMA). While stirring, the air in the reaction vessel was fully replaced with $\mathrm{N}_{2}$ gas. Next, $0.1 \mathrm{~g}$ of ceric ammonium nitrate (CAN) and $15 \mathrm{ml}$ of $0.1 \mathrm{~N}$ nitric acid was added, and the mixture was stirring for 1 hour at $30^{\circ} \mathrm{C}$. Finally, $3 \mathrm{ml}$ of a $1 \%$ aqueous solution of hydroquinone was added to stop the reaction, and the resulting DDMC was purified by water dialysis using a cellophane tube to remove any unreacted MMA, ceric salts and nitric acid.

*Corresponding authors: Yasuhiko Onishi, Ryujyu Science Corporation 39-4 Kosora-cho, Seto, Aichi 489-0842, Japan, Fax: +81-561-84-3227; E-mail: vyx00545@nifty.ne.jp

Yuki Eshita, Department of Infectious Disease Control, Faculty of Medicine, Oita University, 1-1 Idaigaoka, Hasama-machi, Yufu-shi, Oita Prefecture 879-5593, Japan, Fax: +81-97-586-5701; E-mail: yeshita@oita-u.ac.jp

Received April 18, 2012; Accepted May 14, 2012; Published May 31, 2012

Citation: Eshita Y, Ji RC, Onishi M, Mizuno M, Yoshida J, et al. (2012) Supramolecular Facilities to Melanoma Cells B16F10 with Nanoparticles of a DEAE-Dextran-MMA Copolymer-Paclitaxel Complex. J Nanomed Nanotechol S5:002. doi:10.4172/2157-7439.S5-002

Copyright: ( 2012 Eshita Y, et al. This is an open-access article distributed under the terms of the Creative Commons Attribution License, which permits unrestricted use, distribution, and reproduction in any medium, provided the original author and source are credited. 
Citation: Eshita Y, Ji RC, Onishi M, Mizuno M, Yoshida J, et al. (2012) Supramolecular Facilities to Melanoma Cells B16F10 with Nanoparticles of a DEAE-Dextran-MMA Copolymer-Paclitaxel Complex. J Nanomed Nanotechol S5:002. doi:10.4172/2157-7439.S5-002

Page 2 of 6

\section{DDMC-paclitaxel complexation}

The DDMC-paclitaxel was obtained by adding paclitaxel as a guest to $5 \mathrm{ml}$ of $2 \%$ DDMC. Two samples were prepared, contained 0.385 or $0.709 \mathrm{mg} / \mathrm{ml}$ paclitaxel. For all two samples, the grafting rate was $102 \%$ and DDMC concentration was $9.6 \mathrm{mg} / \mathrm{ml}$.

\section{Characterization of the DDMC-paclitaxel complex}

Particle size distribution and the $\zeta$-potential of the DDMCpaclitaxel complex were measured using dynamic light scattering and particle electrophoretic mobility (SZ-100 nanopartica series instrument; HORIBA, Ltd.). Scanning electron microscopy of freezedried DDMC-paclitaxel complex was done using a HITACHI S-4800 (Hitachi). Absorbance of the DDMC-paclitaxel complex in solution was measured at a wavelength of $227 \mathrm{~nm}$ and light path of $10 \mathrm{~mm}$ using a NanoDrop 2000c (Thermo Fisher Scientific Inc).

\section{MTT (WST8) assay}

Cell survival was determined using MTT assays with water-soluble tetrazolium salts, a series of water soluble dyes suitable for MTT assays. In this method, cells were plated on 96-well tissue culture plates at a density of 10,000 cells/well to ensure that the reach optimal population density was reached within 24-48 hours. Next, the indicated concentrations of DDMC-paclitaxel complex or paclitaxel alone were added to each well, to a final volume of $0.1 \mathrm{ml}$. The culture medium contained up to $10 \%$ fetal bovine serum. Cell Counting Kit-8 (CCK-8; Dojindo Molecular Technologies Inc.) solution was added to each well and the plate was incubated under $\mathrm{CO}_{2}$ at $37^{\circ} \mathrm{C}$ for 24 or 48 hours. After adding $10 \mu \mathrm{l}$ of CCK- 8 solution to each well, the plate was gently mixed and incubated under $\mathrm{CO}_{2}$ at $37^{\circ} \mathrm{C}$ for $2-4$ hours. The optical density of each well was measured at $450 \mathrm{~nm}$ and cell survival was calculated using the following formula:

\section{Cell survival $(\%)=[(\mathrm{As}-\mathrm{Ab}) /(\mathrm{Ac}-\mathrm{Ab})] \times 100$}

Where As = absorbance of the sample, Ac = absorbance of the control well (no cells) and $\mathrm{Ab}=$ absorbance of the blank well.

\section{Results \\ DDMC-paclitaxel complex}

A complex consisting of DDMC and paclitaxel (DDMCpaclitaxel) was generated using a novel antitumor alkaloid paclitaxel as the guest, with DDMC as the host. The particle size distribution and $\zeta$-potential of the DDMC-paclitaxel complex were measured in this study by dynamic light scattering and particle electrophoretic mobility. Furthermore, Scanning Electron Microscopy (SEM) (Figure 1) was used to determine the size and shape of the freeze-dried DDMCpaclitaxel complex, which revealed the complex formed uniform cubic particles with a diameter of $200-300 \mathrm{~nm}$ on dynamic light scattering (Figure 2). Particle size determined by SEM (Figure 1) was 300-500 $\mathrm{nm}$, similar to that determined by dynamic light scattering.

Particle size of $300-500 \mathrm{~nm}$ determined by SEM (Figure 1) is thought much larger than real particle size, because DDMC particle form cluster by its association in order to use the freeze-dried sample. Particle size of 200-300 nm at dynamic light scattering shows really particle size. $270 \mathrm{~nm}$

The value at peck of particle size distribution in this range shows

The $\zeta$-potential of the outer layer of the particles, outside of the electric double layer, was $+36 \mathrm{mV}$, which helps to stabilize the dispersion of the DDMC-paclitaxel complex. Considering that the particle size of DDMC is approximately $100 \mathrm{~nm}$, it seems that the DDMC-paclitaxel complex forms clusters to make stable polymeric micelles [19].

Only paclitaxel has an absorbance at a wavelength of $227 \mathrm{~nm}$ owing its $\pi$-electron resonance.

Absorbance of DDMC-paclitaxel complex in solution was measured at a wavelength of $227 \mathrm{~nm}$ (light path, $10 \mathrm{~mm}$ ), which yielded an absorbance coefficient $(\varepsilon)$ of $62.4 \times 10^{4} \mathrm{M}^{-1} \mathrm{~cm}^{-1}$ [19]. As shown in Figure 3, this is much larger than that of paclitaxel alone, which was $3.27 \times 10^{4} \mathrm{M}^{-1} \mathrm{~cm}^{-1}$ in acetone $/ \mathrm{H}_{2} \mathrm{O}(50: 1), 2.8 \times 10^{4} \mathrm{M}^{-1} \mathrm{~cm}^{-1}$ in $\mathrm{CH}_{3} \mathrm{CN}: \mathrm{H}_{2} \mathrm{O}(4: 1)$ and $2.6 \times 10^{4} \mathrm{M}^{-1} \mathrm{~cm}^{-1}$ in $\mathrm{MeOH}: \mathrm{H}_{2} \mathrm{O}(1: 1)$. This increase in absorbance may be due to the strong photoconductive property of paclitaxel by promoting $\pi$-electron resonance, which forms a line dependent on the supramolecular $\pi$ stack structure of paclitaxel self-integrated into DDMC [20]. These properties may also explain why the DDMC-paclitaxel complex showed high reactivity and specificity for its target substrate in melanoma cells which are known broadly as the most lethal cancer cell.

\section{Survival analysis by MTT assay (WST8)}

The results of a direct MTT assay (WST8) showed a positive correlation between cell number and absorbance (i.e., optical density),

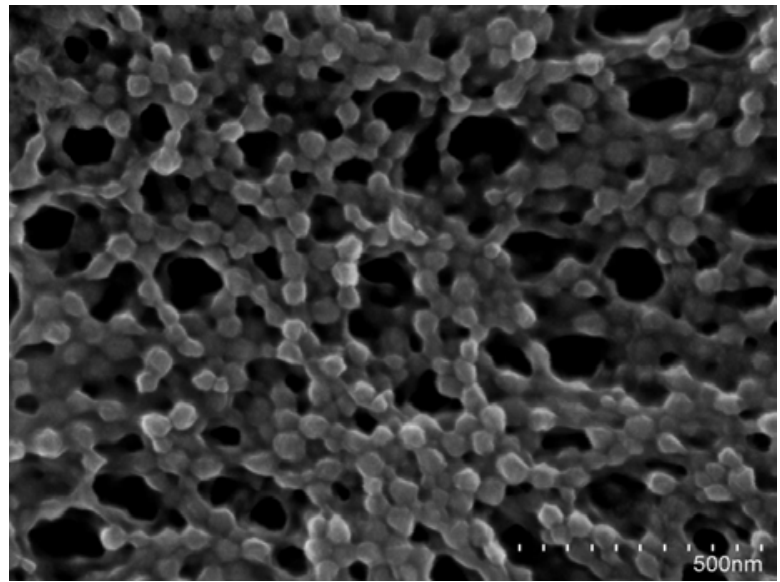

Figure 1: Scanning electron microscopic image (HITACHI S-4800) of the freeze-dried DDMC-paclitaxel complex taken at an accelerating voltage of 5 $\mathrm{kV}$

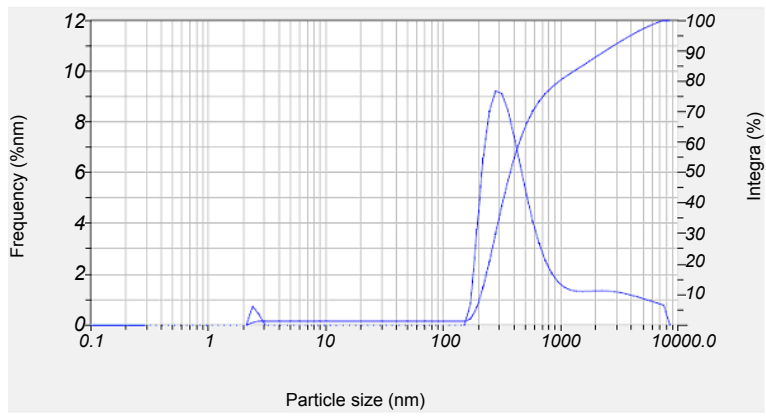

Figure 2: Particle size distribution and $\zeta$-potential of the DDMC-paclitaxe complex determined by dynamic light scattering and particle electrophoretic mobility. 
and the efficacy of paclitaxel on melanoma cells in vitro. Melanoma cells are well known to show resistance to paclitaxel, as indicated in the survival curves shown in Figure 4 and Figure 5 with asymptote of $\mathrm{P}(\mathrm{A})$ and $\mathrm{P}(\mathrm{B})$.

The different concentrations of DDMC-paclitaxel complex or paclitaxel alone were added to each well contenting a culture medium with $10 \%$ fetal bovine serum, and the plate was incubated under $\mathrm{CO}_{2}$ at $37^{\circ} \mathrm{C}$ for 24 or 48 hours. However, survival (\%) of both DDMCpaclitaxel complex and paclitaxel alone at 48 hours were lower than one at 24 hours as reported in the Figure 4 and Figure 5, which show the same convex curve of PTX alone that $\mathrm{P}(\mathrm{A})$ and $\mathrm{P}(\mathrm{B})$ are asymptotic, and a straight line of DDMC-PTX complex following MichaelisMenten kinetic.

The survival curves, which are inverse to paclitaxel concentrations, indicate that gene expression should be taken into account for the concentration-dependent survival at low paclitaxel concentrations (event A) and is negatively associated with survival at higher concentrations of paclitaxel (event B). In this way, the probability of survival is expressed as the product of the probability of $\mathrm{P}(\mathrm{A})$ positively and $\mathrm{P}(\mathrm{B})$ negatively, represented as $\mathrm{A} \cap \mathrm{B}$, where the probability of survival is the product of the probability $\mathrm{P}(\mathrm{A})$ and gene expression survival that is positively dependent on low paclitaxel concentrations and the probability $\mathrm{P}(\mathrm{B})$ of gene expression survival that is negatively dependent on high paclitaxel concentrations. Thus, the probability $\mathrm{A} \cap \mathrm{B}$ is the phenomenon that events $\mathrm{A}$ and $\mathrm{B}$ occur in event $(\mathrm{A}, \mathrm{B})$. When events $A$ and $B$ are independent of each other, the probability $\mathrm{P}(\mathrm{A} \cap \mathrm{B})$ is represented by the following formula.

$$
\mathrm{P}(\mathrm{A} \cap \mathrm{B})=\mathrm{P}(\mathrm{A}) \cdot \mathrm{P}(\mathrm{B})
$$

Where: $\mathrm{P}(\mathrm{A} \cap \mathrm{B})=$ probability of event $\mathrm{A}$ and $\mathrm{B} ; \mathrm{P}(\mathrm{A})=$ the probability of event $A$ and $P(B)=$ the probability of event $B$. Using this Equation, the convex curve is used to assume that $\mathrm{P}(\mathrm{A})$ and $\mathrm{P}(\mathrm{B})$ are asymptotic ${ }^{* *}$.

Dr. Miyano of the University of Tokyo has conducted extensive research into the resistance of melanoma cells to paclitaxel (here, event A). The survival of melanoma cells resistant to paclitaxel has been extensively analyzed using DNA microarrays and dynamic Bayesian analyses. In such studies, gene expression was measured for 24 hours after treatment, which showed that gene clustering over time in melanoma cells. These findings obtained from dynamic Bayesian analysis in combination with non-linear regression were confirmed using data from DNA microarrays [21].

One hour after the administration of paclitaxel, the RBM23 gene, a known target of paclitaxel, acted as a hub and interacted with the TUBA4A gene, which encodes tubulin $a-4 \mathrm{~A}$ chain. Two hours later, TXNIP gene was found to act as a key gene that was not responsive to paclitaxel in the treatment of breast cancer. Four hours later, the DNA microarrays revealed the activation of several genes downstream of EGR1 and TXNIP. Six hours later, CYR61, which is involved in the resistance to paclitaxel in breast cancer, becomes more active and is continued to be influenced by EGR1. In this way, cancer cells exposed to anticancer drugs acquire resistance to the drug over time, and show complex cellular behaviors.

In this experiment, it can be explained using factor analysis to examine the effects of low paclitaxel concentrations on survival and gene expression of melanoma cells. However, we considered that paclitaxel was unlikely not to participate in stabilization of tubulin (i.e., tubulin polymerization), even at low paclitaxel concentrations. At high
UV absorbance (227nm) vis the paclitaxel conc

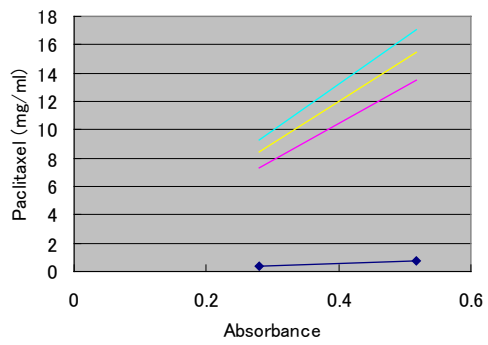

$\rightarrow$ DDMC/PTX e $62.4 \times 10^{\wedge}$ ( $\mathrm{H} 2 \mathrm{O})$

PTX e $3.27 \times 10^{\wedge} 4$ (acetone: $\mathrm{H} 2 \mathrm{O}=50: 1$ PTX e $2.8 \times 10^{\wedge} 4$ $(\mathrm{CH} 3 \mathrm{CN}: \mathrm{H} 2 \mathrm{O}=4: 1)$ PTX e $2.6 \times 10^{\prime 4}$ $(\mathrm{MeOH}: \mathrm{H} 2 \mathrm{O}=1: 1)$

Figure 3: Absorbance of the DDMC-paclitaxel complex solution measured at a wavelength of $227 \mathrm{~nm}$ and light path of $10 \mathrm{~mm}$.

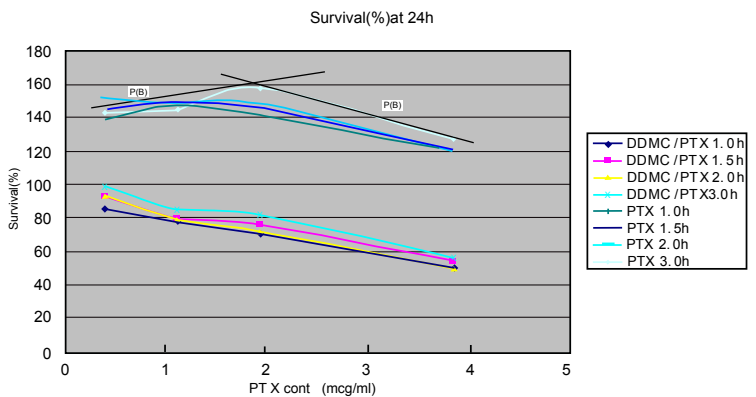

Figure 4: Survival of B16F10 melanoma cells treated with paclitaxel or the DDMC-paclitaxel complex for 24 hours. Survival was determined using the MTT (WST8) method after incubated under $\mathrm{CO}_{2}$ at $37^{\circ} \mathrm{C}$ for $1,1.5,2$, and 3 hours, respectively.

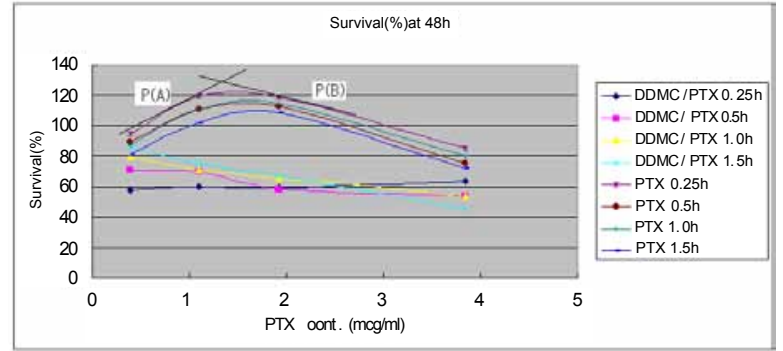

Figure 5: Survival of B16F10 melanoma cells treated with paclitaxel or the DDMC-paclitaxel complex for 48 hours. Survival was determined using the MTT (WST8) method after incubated under $\mathrm{CO}_{2}$ at $37^{\circ} \mathrm{C}$ for $0.25,0.5,1$, and 1.5 hours, respectively.

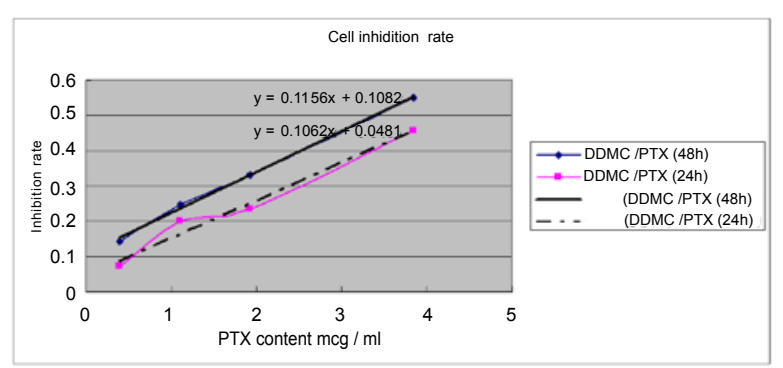

Figure 6: Relationship between Cd and paclitaxel concentration. Both Tubulin polymerization and cell death $(\mathrm{Cd})$ rates can be expressed by enzymatic kinetic parameters following Michaelis-Menten Eq. 
concentrations, however, the enhanced tubulin polymerization will be progress, unable to inhibit the responses to paclitaxel. Therefore, the reduced survival dependent on paclitaxel concentrations (i.e., event B) becomes dominant and the efficacy of paclitaxel becomes more apparent.

By contrast, the responses of melanoma cells to the DDMCpaclitaxel complex are much more specific without event A. Of note, low concentrations of the DDMC-paclitaxel complex markedly inhibited the increase in number of melanoma cells, with a linear negative correlation between paclitaxel concentration $[\mathrm{E}]_{0}$ and survival rate. This means there are no these resistances of melanoma cells to DDMC-paclitaxel complex.

\section{Michaelis-Menten kinetics}

In other words, the relationship between the cell death $(\mathrm{Cd})$ rate $(\mathrm{Cd} / \mathrm{dt})$ and tubulin polymerization $(\mathrm{P})$ rate $(\mathrm{dp} / \mathrm{dt})$ will assume the following Equation, as modified from Cheng and Prusoff [22]:

$$
\mathrm{Cd} / \mathrm{dt}=\mathrm{adp} / \mathrm{dt}+\mathrm{C}_{1}
$$

Where, $\mathrm{a}$ is a constant and $\mathrm{C}_{1}$ is a device constant corresponding to $\mathrm{a}>0, \mathrm{C}_{1}>0$. The rate of tubulin polymerization $\mathrm{V}=\mathrm{dp} / \mathrm{dt}$ can also be expressed using a Michaelis-Menten Equation derived its S-shaped curve, as follows

$$
\mathrm{v}=\frac{\kappa \mathrm{cat}[\mathrm{E}]_{0}[\mathrm{~S}]_{0}^{\mathrm{n}}}{[\mathrm{S}]_{0}{ }^{\mathrm{n}}+\mathrm{Km}}
$$

Where $\mathrm{K}_{\mathrm{m}}=$ Michaelis constant, $[\mathrm{S}]_{0}=$ initial tubulin concentration and $\mathrm{n}=$ Hill coefficient. In this case, because $\mathrm{n}>1$, mutual interactions between numerous points occur, which fit an S-shaped curve. The stability of the enzyme-substrate complex is shown as $1 / \mathrm{K}_{\mathrm{m}}$, and larger for DDMC-paclitaxel than for paclitaxel alone, corresponding to $[\mathrm{S}]_{0}{ }^{\mathrm{n}}$ $>>\mathrm{K}_{\mathrm{m}}$. The Equation

$$
\mathrm{V}=\text { кcat }[\mathrm{E}]_{0}
$$

can be substituted with the expression from (1), as follows:

$$
\mathrm{Cd} / \mathrm{dt}=\mathrm{a \kappa cat}[\mathrm{E}]_{0}+\mathrm{C}_{1}
$$

and integrated into:

$$
\mathrm{Cd}=\mathrm{a} \kappa \mathrm{cat}[\mathrm{E}]_{0} \mathrm{t}+\mathrm{C}_{1} \mathrm{t}
$$

From this, the rate of tubulin polymerization $\mathrm{V}$ can be express using enzymatic parameters for Cd. In these Equations, $[\mathrm{E}]_{0}=$ initial paclitaxel concentration as an enzyme.

In Figure 6, incubation with MTT for 24 and 48 hours yielded the following Equation:

$$
\begin{aligned}
& \mathrm{Cd}=0.1156[\mathrm{E}]_{0}+0.1082 \\
& \mathrm{Cd}=0.1062[\mathrm{E}]_{0}+0.0481
\end{aligned}
$$

Thus, 0.1082 and 0.0481 represent the constants for $[E]_{0}$ at 24 and 48 hours, respectively.

From Equation (5), the plots of $\mathrm{C}_{1} \mathrm{t}$ with time $\mathrm{t}$ must be extrapolated to 0 at $\mathrm{t}=0$. Accordingly, when $\mathrm{C}_{1} \mathrm{t}=0.1082$ at 24 hours and 0.0481 at 48 hours are plotted, it can be almost extrapolated to 0 at time $\mathrm{t}=0$ from Figure 7. This confirms the assumption in Equation (5) that the relationship between $[\mathrm{E}]_{0}$ for paclitaxel and the probability of $\mathrm{Cd}$ forms a straight line. From these results and based on $\mathrm{V}=\mathrm{dp} /$ $\mathrm{dt}$, the DDMC-paclitaxel complex promotes enzymically tubulin polymerization that can be expressed using Michaelis-Menten kinetics added the Hill coefficient [23]. These phenomena also demonstrate the supramolecular properties of the DDMC-paclitaxel complex.

\section{Allosterical enzymatic reactions}

The results also indicate that these enzymatic reactions allosterically promote tubulin polymerization in cells. Hydrophobic interactions between the polymer and substrate, with paclitaxel located in socalled the hydrophobic pocket, allow paclitaxel to selectively react with tubulin as indicated in Figure 8.

This effect is not apparent with paclitaxel alone, and is less susceptible to interference from other signals. The results also provide evidence that the DMC-paclitaxel complex causes a supramolecular reaction involving allosteric promotion, as in Equation (2). The Hill coefficient included in Equation (2) supports the likelihood of allosteric cooperation as it represents the strength of cooperative molecular joints. These phenomena may depend on the supramolecular characteristics of clathrate compounds as the paclitaxel guest is complexed with DDMC as the host. Therefore, the DDMC-paclitaxel complex shows marked substrate specificity, consistent with artificial enzymes.

This substrate specificity of the DDMC-paclitaxel complex promotes enzymically a reaction between paclitaxel and tubulin, the target of paclitaxel, and avoids potential interference from changes in

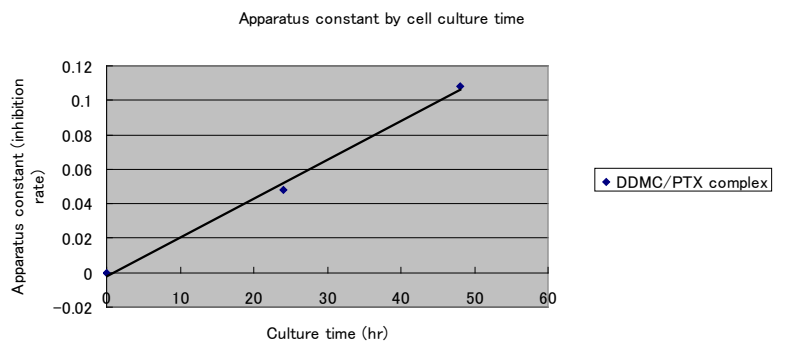

Figure 7: Relationship between the inhibition rate constant $C_{1}$ and paclitaxe concentration.

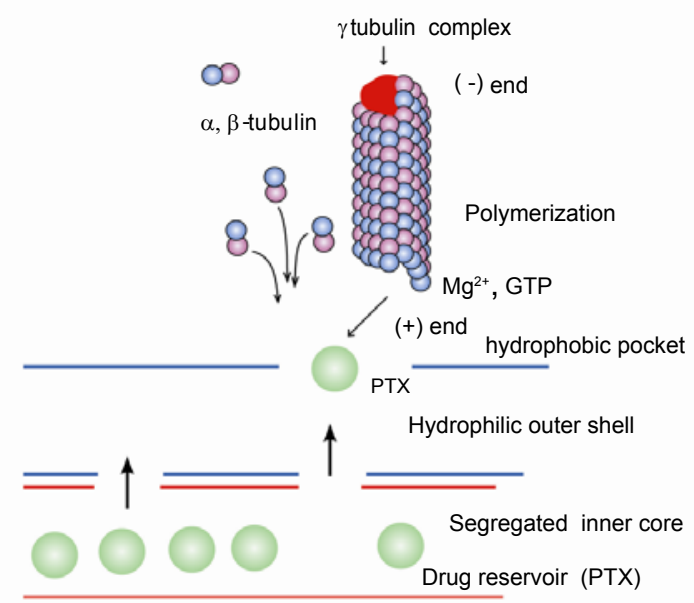

Figure 8: Schematic representation of $\alpha, \beta$-tubulin dimer polymerization showing the relationship between the DDMC-paclitaxel complex and $\alpha, \beta$ tubulin. The $\alpha, \beta$-tubulin dimer orientates with the active site (i.e., paclitaxel) of the DDMC-paclitaxel complex. 
gene expression that may affect the survival response to paclitaxel, even at low concentrations.

Paclitaxel can be conjugated to a variety of carriers, including polyglutamate and albumin, or encapsulated in cationic liposomes. Using these carriers, paclitaxel is thought to be transported into and released directly in cells, thus improving its efficacy. However, the DDMC-paclitaxel complex is not degraded in the cell, and its efficacy may be enhanced by remaining in supramolecular form.

\section{Discussion}

\section{Thermo dynamic consideration of supramolecular allosteric binding}

Supramolecular allosteric binding, such as binding of molecular oxygen to hemoglobin, is a phenomenon that increases the reactivity of the active site and other substrate binding site. For hemoglobin, oxygen acts as an effector and as the substrate. Binding of the molecule to the allosteric binding site on one subunit enhances the affinity of the other binding sites by inducing structural changes. Thus, the allosteric properties of these supramolecules resemble those of enzyme-substrate interactions.

In the case of enzyme-substrate interactions with DDMC-paclitaxel complex to melanoma cells $\mathrm{B} 16 \mathrm{~F} 10$, the allosteric properties from supramolecules may yield entropy decreases (entropy trap) depending on the selectively react with tubulin and the strain of substrate under its stress from molecular structure as indicated in Figure 8.

At same time, an enthalpy decreases yield depending on adhesion of substrate by supramolecules structure of DDMC-paclitaxel complex.

Paclitaxel is an anticancer agent that was originally isolated from the bark of the yew that promotes tubulin polymerization and inhibits $\beta$-tubulin depolymerization. The DDMC-paclitaxel complex is formed by self-assembly and aggregation owing to the supramolecular $\pi$ stack as shown in Figure 3, forming particles of approximately $270 \mathrm{~nm}$ in size. Electrostatic and hydrophobic interactions between the cationic DDMC-paclitaxel complex and its substrate, the $\alpha, \beta$-tubulin dimer, orientate $\beta$-tubulin with the hydrophobic pocket of the DDMCpaclitaxel complex, which promotes to polymerize the $\alpha, \beta$-tubulin dimer through the activity sight of paclitaxel consistent with MichaelisMenten kinetics. The stability of the enzyme (DDMC-paclitaxel)substrate ( $\alpha, \beta$-tubulin dimer) complex (Michaelis complex) can be represented as $1 / \mathrm{K}_{\mathrm{m}}$, although is probably very large, it cause dynamic instability in the tubulin dimers to stop the Treadmill of tubulin Protomers. This $\alpha, \beta$-tubulin dimer and DDMC-paclitaxel complex also contain $\mathrm{Mg}^{2+}$ and GTP on the leading edge, which may also be involved in tubulin polymerization, as follows:

$\mathrm{nTaTb}+\mathrm{GTP}+\mathrm{Mg}^{2+}+$ DDMC-paclitaxel $\rightarrow$ Complex $\rightarrow(\mathrm{TaTb}) \mathrm{n}$ $+\mathrm{GDP}+\mathrm{Mg}^{2+}+\mathrm{DDMC}$-paclitaxel

Where $\mathrm{TaTb}$ is the $\alpha, \beta$-tubulin dimer.

The catalytic power of enzymes to efficiently form transition states has been proposed to involve an equilibrium between the Michaelis complex and a stabilized transition state.

Gibbs free energy in the transition state is considered.

$$
\Delta \mathrm{G}^{\ddagger}=\Delta \mathrm{H}^{\ddagger}-\mathrm{T} \Delta \mathrm{S}^{\ddagger}
$$

Where, $\Delta \mathrm{G}^{\ddagger}$ means free energy of activation, $\Delta \mathrm{S}^{\ddagger}$ means entropy of activation, and $\Delta \mathrm{H}^{\ddagger}$ also means enthalpy of activation.
Figure 9 shows potential energy curve and activation energy $\mathrm{E}_{\mathrm{a}}$

Where, $\mathrm{E}_{\mathrm{a}} \fallingdotseq \Delta \mathrm{H}^{\ddagger}$.

With paclitaxel, many signals from gene expression in melanoma cells yield a huge $\Delta \mathrm{G}^{\ddagger}$ owing to large $\Delta \mathrm{S}^{\ddagger}$ and large $\Delta \mathrm{H}^{\ddagger}$ as in Figure $4 \mathrm{C}$.

As $\mathrm{R} \propto \mathrm{e}^{\Delta \mathrm{H} \neq / \mathrm{RT}}$ with apoptosis for melanoma cell( $\mathrm{R}=$ rate constant), melanoma cell can overcome paclitaxel in a low concentration.

On the other hands, Figure 9 shows small activation energy $\mathrm{E}_{\mathrm{a}}{ }^{\prime}$ with DDMC-paclitaxel complex, and the enzyme facility from supramolecule yield a small $\Delta \mathrm{G}^{\ddagger}$ owing to low $\Delta \mathrm{S}^{\ddagger}$ and low $\Delta \mathrm{H}^{\ddagger}$, that is why apoptosis for melanoma cell should be progress.

\section{Supramolecular template}

As shown in Figure 8, the a-tubulin side is a negative edge, and the $\beta$-tubulin side is a positive edge.

During polymerization, both the $\alpha$ - and $\beta$-subunits of the tubulin dimer are bound to a molecule of GTP. Much microtubule places a negative edge in Microtubule Organizing Center (MTOC), centrosome in the animal cell, to extend the $(+)$ growth edge to each place of the cell. Of course, the other microtubules formed outside of centrosome are searched and transported to MTOC that is associated to unification [24]. In one embodiment, the tubulin-binding agent is a microtubule stabilizing agent.

Cell division is usually initiated when polymerization ceases to form the sufficient long hollow tube to provide support for myosin and actin located on the cell surface by gathering its 13 fibers. The DDMCpaclitaxel complex stabilizes the $\alpha, \beta$-tubulin dimer, which is therefore unable to stop polymerization, promoting cell apoptosis following the formation of numerous poor-quality short hollow tubes. Figure 10 shows the diffusion of paclitaxel to the outer surface, the coordination of $\alpha, \beta$-tubulin dimmer on the DDMC/PTX complex, and subsequent growth of the $\alpha, \beta$-tubulin dimer on the DDMC/PTX complex. This reaction may be accelerated by the orientation of the $\alpha, \beta$-tubulin dimer to paclitaxel within the hydrophobic pocket of the DDMC-paclitaxel complex. The resulting polymerization should be coordinated by both the growing end of the $\alpha, \beta$-tubulin polymer and the $\alpha, \beta$-tubulin dimer on a supramolecular template, and one-dimensional Brownian motion

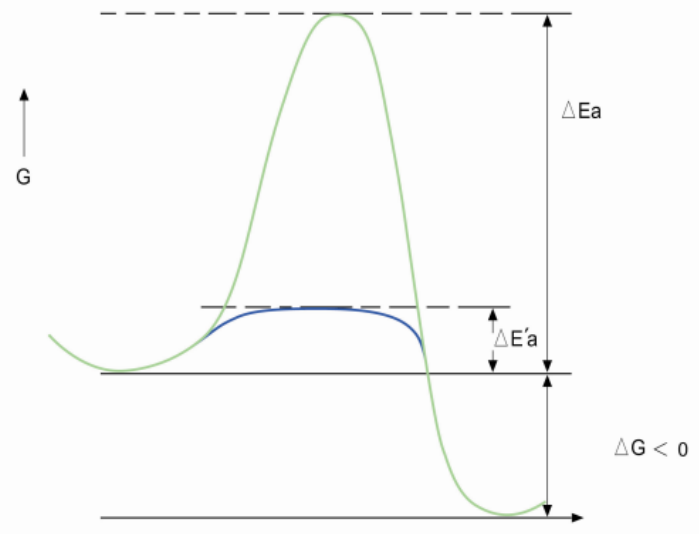

Figure 9: Potential energy curve of paclitaxel (green) and DDMC-paclitaxe complex (blue). Ea: activation energy of paclitaxel, Ea': activation energy of DDMC-paclitaxel complex. 
Citation: Eshita Y, Ji RC, Onishi M, Mizuno M, Yoshida J, et al. (2012) Supramolecular Facilities to Melanoma Cells B16F10 with Nanoparticles of a DEAE-Dextran-MMA Copolymer-Paclitaxel Complex. J Nanomed Nanotechol S5:002. doi:10.4172/2157-7439.S5-002

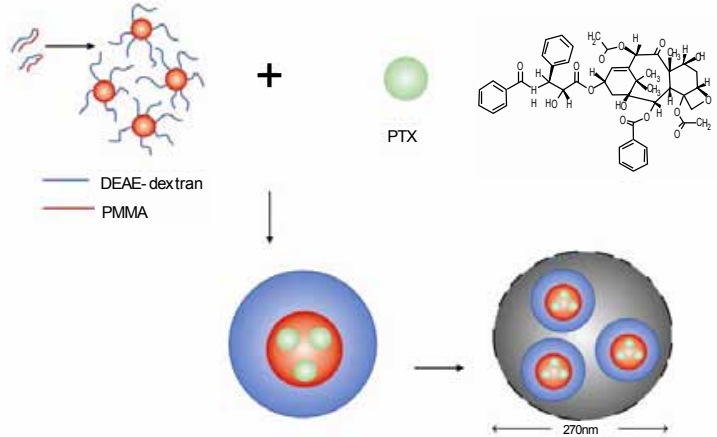

Figure 10: Schematic representation of the DDMC-paclitaxel complex. Simplified structures are shown. The DDMC-paclitaxel complex $(\sim 270 \mathrm{~nm})$ will consists of more than $8.1 \times 10^{3}$ DDMC molecules and $6.7 \times 10^{6}$ paclitaxel molecules.

is accompanied by electrostatic interactions with the DDMC-paclitaxel complex. This coordination polymerization will proceed as a result of Brownian motion [25].

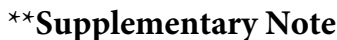
$(1-x))$.

When $P(A)$ : ax and $P(B): b(1-x),(A \cap B)$ is shown as $y=(a x)(b$

The secondary function (convex curve) of $\mathrm{y}=(\mathrm{ax})(\mathrm{b}(1-\mathrm{x}))$ makes both $y=a x$ and $y=b(1-x)$

an asymptote in a range of $\mathrm{a}>0, \mathrm{~b}>0$ and $1>\mathrm{x}>0$.

\section{Disclosure of potential conflicts of interest}

No potential conflicts of interest were disclosed.

\section{Acknowledgements}

A portion of this research was carried out with the support of a Japanese Ministry of Health, Labour, and Welfare Scientific Research Grant (H18-ShinkoIppan-009, H20-Shinko-Ippan-015, H23-Shinko-Ippan-015) and the Japan Society for the Promotion of Science Research Grant (Basic C 18580310, Basic C 23590803, Basic B Overseas Science 20401050).

\section{References}

1. Matsumura $Y$, Maeda $H$ (1986) A new concept for macromolecular therapeutics in cancer chemotherapy: mechanism of tumoritropic accumulation of proteins and the antitumor agent smancs. Cancer Res 46: 6387-6392.

2. Allen TM, Chonn A (1987) Large unilamellar liposomes with low uptake into the reticuloendothelial system. FEBS Lett 223: 42-46.

3. Oku N, Namba Y, Okada S (1992) Tumor accumulation of novel RES-avoiding liposomes. Biochim Biophys Acta 1126: 255-260.

4. Savic R, Luo L, Eisenberg A, Maysinger D (2003) Micellar nanocontainers distribute to defined cytoplasmic organelles. Science 300: 615-618.

5. Hamblin MR, Miller JL, Rizvi I, Ortel B, Maytin EV, et al. (2001) Pegylation of a chlorin(e6) polymer conjugate increases tumor targeting of photosensitizer. Cancer Res 61: 7155-7162.
6. Nishiyama N, Nori A, Malugin A, Kasuya Y, Kopecková P, et al (2003) Free and N-(2-Hydroxypropyl)methacrylamide Copolymer-bound Geldanamycin Derivative Induce Different Stress Responses in A2780 Human Ovarian Carcinoma Cells. Cancer Res 63: 7876-7882.

7. Willstatter R, Pfannenstiel Al (1920) Über Succinyldiessigsäureester. Justus Liebigs Ann Chem 422: 1-15.

8. Onishi Y, Maruno S, Kamiya S, Hokkoku S, Hasegawa M (1978) Preparation and characteristics of dextran-methyl methacrylate graft copolymer. Polyme 19: $1325-1328$

9. Onishi $Y(1980)$ Effects of dextran molecular weight on graft copolymerization of dextran-methyl methacrylate. Polymer 21: 819-824.

10. Onishi Y, Maruno S, Hokkoku S (1979) Graft copolymerization of methy methacrylate onto dextran and some properties of copolymer. Kobunsh Ronbunshu 36: 535-541.

11. Onishi Y, EshitaY, Murashita A, Mizuno M, Yoshida J (2005) Synthesis and characterization of 2-diethylaminoethyl (DEAE)-dextran-MMA graft copolymer for non-viral gene delivery vector. J Appl Polym Sci 98: 9-14.

12. Onishi Y, Eshita Y, Murashita A, Mizuno M, Yoshida J (2007) Characteristics of 2-diethylaminoethyl (DEAE)-dextran-MMA graft copolymer as a non-viral gene carrier. Nanomedicine 3: 184-191.

13. Eshita Y, Higashihara J, Onishi M, Mizuno M, Yoshida J, et al. (2009) Mechanism of introducing exogenous genes into cultured cells using DEAEdextran- MMA graft copolymer as non-viral gene carrier. Molecules 14: 26692683.

14. Onishi $Y$, Eshita $Y$, Mizuno M (2009) Delivery Technologies fo Biopharmaceuticals: Peptides, Proteins, Nucleic acids and Vaccines. (John Wiley \& Sons, West Sussex), UK

15. Onishi Y, Eshita Y, Murashita A, Mizuno M, Yoshida J (2008) A novel vector of 2-diethyl aminoethyl(DEAE)-dextran-mma graft copolymer for non-viral gene delivery. J Gene Med 10: 472.

16. Onishi Y, Eshita Y, Mizuno M (2009) Advances in Nanotechnology. Nova Science Publishers, New York.

17. Onishi Y, Eshita Y, Mizuno M (2010) DEAE-Dextran and DEAE-Dextran-MMA graft copolymer for nanomedicine. Polymers Research Journal 3: 415-453.

18. Eshita Y, Junko Higashihara, Masayasu Onishi, Masaaki Mizuno, Jun Yoshida et al. (2011) mechanism of the introduction of exogenous genes into cultured cells using DEAE-dextran-MMA graft copolymer as a non-viral gene carrier. II. Its Thixotropy Property. J Nanomedic Nanotechnol 2: 1-8.

19. Yguerabide J, Yguerabide EE (1998) Light-scattering submicroscopic particles as highly fluorescent analogs and their use as tracer labels in clinical and biological applications. Anal Biochem 262: 137-156.

20. NakanoT, Takewaki K, YadeT, Okamoto $Y$ (2001) Dibenzofulvene, a 1,1 diphenylethylene analogue, gives a $\pi$-stacked polymer by anionic, free-radical and cationic catalysts. J Am Chem Soc 123: 9182-9183.

21. Miyano S (2011) Grants-in-Aid for Scientific Research on Innovative Areas, MEXT, Japan (Project No. 4201), Cancer \& Supercomputer. CICSJ Bulletin 29: 42-48.

22. Cheng Y, Prusoff WH (1973) Relationship between the inhibition constant (KI) and the concentration of inhibitor which causes 50 per cent inhibition (150) of an enzymatic reaction. Biochem Pharmacol 22: 3099-3108.

23. Hill AV (1910) The possible effects of the aggregation of the molecules of haemoglobin on its dissociation curve. J Physiol 40.

24. Wadsworth P, Khodjakov A (2004) E pluribus unum: towards a universa mechanism for spindle assembly. Trends Cell Biol 14: 413-419.

25. Minoura I, Muto E (2006) Dielectric measurement of individual microtubules using the electroorientation method. Biophys J 90: 3739-3748. 